\title{
The training of Afghans in the context of the repatriation of Afghan refugees and the reconstruction and development of Afghanistan
}

Introduction

In assessing how best to provide support to the people of Afghanistan in relation to the reconstruction and development of the country, one option which assumes very high priority is the provision of training.

The purpose of this paper is to assist British NGOs to decide how they should most appropriately use their resources in meeting the training needs of the Afghans. It will therefore look at current needs, at how they are being met and at the gaps that exist. It will also consider what lessons can be learnt from experience to date, both in the context of Afghanistan and in comparable situations elsewhere in the world, before making some tentative conclusions. These conclusions can be considered, along with other contributions, at the proposed seminar on training issues on 10 th July 1989.

\section{Current training needs}

There is a considerable shortage of skills in most areas of expertise. Traditional skills, such as those relating to agriculture, have been partly lost, both in Afghanistan and in the refugee camps. The younger generation, in particular, will have been more likely to pick up military skills than agricultural ones over the past ten years. Children in the refugee camps will have had little opportunity to learn agricultural skills by example and may not have had much incentive to learn them.

Further, while the women who have remained behind in Afghanistan may have retained skills in carpet weaving, craft work, tailoring and sewing, the women in the refugee camps have needed the encouragement of NGOs, through income-generation projects, to retain these traditional skills. Thus, only a minority may have continued to practice them.

The availability of skills has also been very badly affected by the large number of deaths occasioned by the war and by the high level of disability.

Some of the more highly qualified Afghans have gone to live in Europe or North America, but these may have misgivings about returning, for one reason or another.

One is therefore talking about focussing training on those who have remained in Afghanistan, or those living as refugees, in the skills which are most needed. Apart from general agricultural skills, those required most urgently are veterinary skills, because of the high level of sickness amongst livestock, technical skills (carpentry, building, tool making, blacksmithery, auto and tractor mechanics, pump maintenance), 
medical skills, tailoring and craft work (as a source of cash).

What is being taught already?

\section{(a) Training inside Afghanistan}

Although most NGOs have had, as an integral objective in their programmes, the training of Afghans, these have covered only a small part of the country.

Training in medical skills has perhaps been the greatest area of NGO involvement. A number of NGOs run hospitals and clinics at which they train Afghans at the same time as providing medical care.

Many of the trainees have been sent to Pakistan for further training, with the expectation that they would return to work in the same establishments. The training courses offered have been for between two days and eighteen months, al though most have been for in excess of three months. There are current efforts to standardise the length of training provided as well as the course content and the levels of attainment to be aimed at. Trainees are normally nominated by local commanders or jirgas so as to ensure that the communities from which trainees come understand the purpose of the training and have identified their expectations, and that these are clear to the trainees. In this way it is hoped that the motivation of the trainees will be largely guaranteed, together with their willingness to return to practice what they have learnt.

The provision of ongoing supervision is something of a hit-andmiss affair. Some areas have medical personnel able and willing to provide the necessary supervision to trainees. In other areas, trainees have to act with little, if any, expert guidance. At times this lack of support leads people to stop practicing what they have learnt or to succumb to the pressure to hand out medication indiscriminately rather than exercise their skills. Very occasionally, trainees may deal with situations which they should have referred to others.

Much of the training in the medical field has been related to curative health care. However, Health Unlimited has been undertaking preventive health care training in the valley where it works, focussing on the training of traditional birth attendants and on the informal transfer of health information in the course of daily interaction.

Apart from the transfer of medical skills, NGOs have recently begun to pass on expertise in the agricultural field as part of their development programmes. This has included the encouragement of farmers to use improved wheat seed produced by the Agricultural Survey of Afghanistan. Some NGOs have engaged agricultural extension workers to promote the use of techniques which benefit from current theoretical knowledge and experience gained from other parts of the country or the world.

NGOs have encountered much interest in the areas in which they have been working in the furtherance of veterinary skills. The 
Dutch Committee for Afghan Refugees has run training programmes for some time. Afghan Medical Aid has recently sent one of its staft on a three month course at the Royal Veterinary College. Health Unlimited has been asked to provide training in veterinary skills by the commander of the area that it works in in northern zabul. It is currently considering whether to run this in the valley concerned or in Quetta, where there are more animals from which to learn. It is possible that a British NGO, VETAID, will run such a course. VETAID has recently agreed with the Islamic Aid Health Centre to carry out a three months survey of animal health in a particular area of Afghanistan as a basis for the establishment of a para-vet training programme in quetta.

There have been some examples of people being sent to Pakistan for training in technical skills.

(b) Training of refugees

(i) NGO Training initiatives

These have taken several forms. Income-generation projects run by NGOs in the refugee camps have resulted in people regaining or developing skills in carpet-making, tailoring, craft work, construction work and pump maintenance. Skills centres in the camps have provided training in carpentry, tool-making, blacksmithery, auto-maintenance etc. Preventive health care training has been organised on a large scale, mostly from Basic Health Units in the camps. Special courses have been put on in Peshawar or quetta providing the full range of skills, although with an emphasis on medical skills.

A recent shift in emphasis has been an increased concentration on teacher training and on training in agricultural skills. The Austrian Relief Committee, for example, is setting up an Agricultural Institute, which it hopes will start in about three months time. It has carried out a survey in the camps of people experienced in agriculture and has come up with about 1,000 refugees. It hopes to run $4 / 5$ month intensive refresher courses to cover farm management, mechanisation, irrigation, animal husbandry etc. It is also hoping to run short courses for people with ten years schooling to train as agricultural extension workers. In addition, it wants to train others on one-year courses, which would be $60 \%$ practical, and $40 \%$ theoretical, using plots of land outside Peshawar, for training in agriculture, animal farming and agricultural workshop techniques. It is interested in training Afghans seconded by their communities inside Afghanistan.

Also of note is the very considerable focus of save the children Fund on training and the thought which they have given to training methodology based on their experience throughout the world. In the context of Afghan refugees, apart from their programme of training representatives of families in preventive health care, they have also sent a number of their Afghan staff on courses run by the Liverpool school of Tropical Medicine. 
There has been a heavy emphasis on the acquisition of basic skills and on health care training.

The number of those trained in basic skills is expected to double from 1988 to 1989 without a proportionate increase in expenditure. This has been achieved by the establishment of mobile training teams, providing shorter training courses, to replace the teams previously based permanently in centres. There is virtually no construction of new centres.

On the health side, the UNHCR will provide additional training and on-the-job training for the entire cadre of health workers to prepare them for their additional responsibilities and functions during repatriation and inside Afghanistan, including the use of medical kits which are being pre-positioned for use in emergencies during repatriation. The target number of trainees for the last half of 1988 was specifically increased for staff responsible for the Expanded Programme of Immunisation operation. Both the male and female Community Health workers training programmes were expanded in 1988 and further expanded in 1989 . For the CHWs already trained (approximately $(2,500)$, refresher training programmes are being implemented. Approximately half a million dollars annually is spent on health training.

There are also several UNHCR projects which involve agricultural activities such as kitchen gardening, poultry farming and animal husbandry, all of which include minor training elements. Separately, under the UNHCR/World Bank income-generating project, there is a training component in the reafforestation sector which includes the training of refugees in forestry operations and extension activities.

Further, under UNHCR's special Programmes in Pakistan, training activities have been organised relating to veterinary services (with some 80 refugees receiving instruction), the expansion of orthopaedic services through the provision of semi-skilled labour to make artificial limbs, and by training Afghans to respond to the psycho-social needs of refugees through an expansion of the psychiatric services.

\section{(iii) Training in the U.K.}

Apart from the secondment of Afghans on short courses in the U.K., mention should be made of an initiative by the British Government in 1982 to bring over, on an annual basis, 20 former students of Kabul University engineering faculty for training in mechanical, electrical and civil engineering. This programme was stopped in 1985 because it was found that the trainees were not willing to return.

What are the gaps?

The main gap is a quantitative one. The need for training far outstrips the possible level of provision. Obviously, there are organisational limits to what NGOs can achieve in the training field. What one wants to avoid is a situation where, during the 
coming year or two, when the need will be greatest, the funding is not available to meet the requests that are made by communities with whom NGOs are working.

What lessons can be learnt from experience to date in the Afghan context?

To look first at the lessons which can be learnt from the initiative taken by the British government this would appear to have failed for a couple of major reasons, among others. First, it does not appear that the trainees were nominated by particular communities. They were simply selected as isolated individuals. As a result they are not sure of having a clear role if they returned. Second, the courses have been lengthy ones, lasting for several years, with the result that the trainees have lost touch with their communities, such as they were, in the refugee camps.

From this and experience elsewhere, the success of a given training initiative does seem to depend very much (a) on the trainees having been nominated by the communities or organisations from which they come (b) the courses being long enough to be of value yet short enough for the trainees not to lose touch with their communities or organisations. Three to six month courses seem to be the ideal from this point of view.

Clearly, this is difficult to achieve within the refugee camps where the purpose of training will be less apparent, given that people do not know if and when they will be going back to Afghanistan. Motivation is therefore a greater problem. On the other hand, it is very much easier to organise training programmes for what is a large captive audience in the camps than for scattered village communities in Afghanistan.

Experience of training both in the camps and in Afghanistan seems to point to the importance of relating training to the perceived needs and expectations of the potential trainees. Health Unlimited's experience of training in preventive health is of interest. Rather than organise formal training courses for groups they found it to be more effective to talk informally with people, both individually and in natural groupings, about current practice and to then gradually build on this to introduce new ideas.

They and others have also found it essential to first persuade people with influence of the value of preventive health information before introducing it to others. Commanders, mullahs and tribal leaders, and men in general, have needed to be convinced before the training of women could be undertaken.

Health Unlimited has also found it necessary to establish credibility in the first instance by providing a curative service.

For most purposes, appropriate training can be provided inside Afghanistan or in Pakistan. Most NGOs have their own specialists who can provide informal training as part of their programmes. If they lack appropriate specialists they can borrow these, on occasion, from other NGOs. They can also obtain specialist backup from the UNDP in Peshawar. However, there are occasions when 
specialists from, say, Europe or North America might be needed to run short training programmes, either in Afghanistan or Pakistan.

There will also be occasions where the level of training available in Afghanistan or Pakistan is not considered adequate by the communities concerned. In such cases secondment to courses in, for example, the U.K., may be appropriate. The Royal veterinary college runs a three months course which it has recently provided free of charge to a member of Afghan Medical Aid's staff. Two members of staff of the Austrian Relief Committee have been attending the Development studies Course at Selly Oak Colleges in Birmingham. Liverpool School of Tropical Medicine runs a three month course in "Management for Primary Health Care" and a one-year "Master of Community Health" course.

Another lesson which can be learnt from experience to date inside Afghanistan is the importance of providing follow-up and supervision. Because Afghanistan lacks any national administrative infrastructure, the provision of even the most basic of services does not benefit from a hierarchy of experience and expertise. NGOs must therefore find ways of structuring follow-up and supervision to support their own trainees until such time as adequate indigenous structures are established. It is considered to be as important for those providing follow-up and supervision to be trained in the appropriate techniques and to have a suitable support structure as to be medically qualified.

\section{What lessons can be learnt from elsewhere in the world?}

clearly, there are many parallels between Afghanistan and elsewhere in the world and there is a body of established wisdom within the field of training methodology.

I will first quote from a guide produced in 1980 by the wHo for teachers of primary health care staff, which includes a process which encapsulates the principles of current thinking. The process is as follows: "The starting point is the community that is, the village, town or region and the people living there. This should be studied using a method called community analysis... The aim of the community analysis is to find out exactly what job the primary health care staff will do. This is written down as a list of tasks... The next stage is to find out what is involved in each of the tasks. This process is called task analysis.... The result of the task analysis is a list of skills, with knowledge and attitudes which the health worker will need for each task. The skills, knowledge and attitudes will be the objective of the course. That is, a list of the things which students will be able to do at the end of the course. The third and final stage is to organise these objectives into a course or a lesson".

The emphasis is therefore on assessing the relevance of the information available to the situation in which the potential trainees find themselves. Teachers are encouraged to spend a lot of time listening before trying to impart information. Trainers should ideally be trained in communication skills, including 
cross-cultural communication skills, listening skills and participatory training skills. Leadership of training should be readily relinquished as trainees take responsibility. Trainers should be taught how best to make use of visual aids. Use should be made of techniques which exist for the follow-up of trainees and for supervision.

It is also important to first establish the expectations of the trainees. Will they require a certificate to establish their credibility with their communities? What does this mean for standardisation of training?

\section{What conclusions can be drawn?}

From the above, one may conclude that there is enormous scope to develop training programmes for Afghans both in Afghanistan and in the refugee camps. In assessing how this is done, the starting point should, as far as possible, be the community from which the potential trainee comes, or to which $s /$ he would return, in the case of refugees. In either case a process needs to be gone through by which there is a process of discussion, in which the potential trainee is involved, as to the relevance of any particular form of training, the level of training to be sought, where it can be obtained and how to go about achieving it. Hopefully, such discussion will include a consideration of whether the training resources exist locally or need to be imported or, alternatively, whether the potential trainees need to travel to a place where the training can be provided. NGOs need to be involved in these discussions insofar as they may be considering the funding of training and need to take cost into account as one of the factors.

In the event that trainers go to Afghanistan or Pakistan from the U.K. they may wish to avail themselves of courses run by Voluntary Service overseas in communication skills (including cross-cultural communication), learning and teaching techniques, adult skills transfer techniques and working with communities. Save the children Fund may also be able to offer the benefit of its expertise in this field.

One is therefore dependent on a large number of different communities deciding their own priorities. It is too early to say what trends there may be and it is therefore necessary for NGos and other funders to be flexible in responding to requests for financial support, whilst requiring that a due process of discussion has taken place as to the expectations of the various parties and the options available. Such financial support could include the funding of NGos to continue with the training programmes which are integral to their work. It could also cover the secondment of people with particular areas of expertise to run training programmes in Afghanistan or Pakistan. Alternatively, it could provide for the secondment of Afghans to train in Pakistan, in the U.K. or in other parts of the world.

A further factor to be taken into account is that the infrastructure will not necessarily exist in Afghanistan to provide trainees with ongoing salaries. NGOs may therefore have to budget to provide ongoing salary support together with an 
appropriate system of follow-up and supervision.

It would appear that most British NGOs have already committed the funds at their disposal. To some extent these may be earmarked for training purposes and some NGOs may feel confident about obtaining additional funding to meet requests for training. However, there may be a need to explore other possible sources of funds, including the ODA, the E.E.C. and UN agencies, in order to avoid a funding shortfall when funds are most needed.

Summary of main points

1) There is enormous scope to train those who have remained in Afghanistan and the refugees in Pakistan in the skills that are most needed in relation to the reconstruction and development of Afghanistan. These are mostly medium-level skills relating to agriculture, primary health care and technical trades. There is a need to map out in some detail where the gaps are in current provision.

2) Training needs should, as far as possible, be identified by the communities concerned and consideration given to whether these can be met locally and, if not, how they are best met. Trainees should be guaranteed of a clear role on completion of their training together with ongoing support and guidance.

3) NGOs and other funders need to be flexible in responding to requests for training.

4) Funding needs to be available on a sufficient scale to accommodate what could be a large number of requests over the next year or two.

Peter Marsden

Information Co-ordinator

British Agencies Afghan Group

27.6 .1989 . 